RESEARCH PAPER RP1555

Part of Journal of Research of the National Bureau of Standards, Volume 31, September 1943

\title{
CALCIUM CHLORIDE COMPOUNDS OF $D-\alpha$-GLUCOHEPTOSE (D-GLYCERO-D-GULO-ALDOHEPTOSE)
}

\author{
By Horace S. Isbell and Harriet L. Frush
}

ABSTRACT

In support of the concept that sugars having like configurations for the atoms comprising the pyranose ring have like properties, it has been found that $D$-glycero$D$-gulo-aldoheptose (formerly $D$ - $\alpha$-glucoheptose) resembles $D$-gulose in that it forms crystalline compounds with calcium chloride, and in that the equilibrium which exists in aqueous solutions is shifted in marked degree by changes in the concentration of calcium chloride. It was shown that the addition of calcium chloride shifts the equilibrium toward the unknown alpha-pyranose modification. The equilibrium optical rotation of $D$-glycero- $D$-gulo-aldoheptose in a 4 -percent aqueous solution in the presence of calcium chloride varies according to the relationship

$$
[\alpha]_{D}^{20}=-20.2+3.54 m-0.067 m^{2},
$$

in which $m$ is the grams of calcium chloride per $100 \mathrm{ml}$ of solution. A crystalline compound, $\beta$-D-glycero-D-gulo-aldoheptose. $\mathrm{CaCl}_{2} \cdot 2 \mathrm{H}_{2} \mathrm{O}$, was prepared and its mutarotation was measured. In 4 percent aqueous solution,

$$
[\alpha]_{D}^{20}=-6.5 \times 10^{-.0072 t}-9.3 \text {. }
$$

\section{CONTENTS}

I. Introduction

II. Effect of calcium chloride on the optical rotation of $D$-glycero-D-guloaldoheptose _............... 164

III. Crystalline calcium chloride compounds of $D$-glycero-D-gulo-aldoheptose 167

IV. Preparation of $\beta$ - $D$-glycero- $D$-gulo-aldoheptose. $\mathrm{CaCl}_{2} \cdot 2 \mathrm{H}_{2} \mathrm{O}_{\ldots} \ldots \ldots$

V. References_._.

\section{INTRODUCTION}

It has been emphasized in previous publications that substances having like configurations for the five carbons comprising the pyranose ring have similar properties, and in aqueous solution establish similar equilibrium states [1,2]. ${ }^{1} \quad$ The correlation of substances of like chemical behavior is useful for the classification of chemical phenomena, for the prediction of new reactions, and for the guidance of research.

Several years ago one of us noted [3] that the addition of calcium chloride causes a marked shift in the equilibrium existing between the various modifications of $D$-gulose in solution, and that under proper conditions exceptionally stable calcium chloride compounds of $D$-gulose may be prepared. $D$ - $\alpha$-glucoheptose, a sugar originally prepared by E. Fischer [4] and now called D-glycero-D-gulo-aldoheptose, ${ }^{2}$ differs

\footnotetext{
1 Figures in brackets indicate the literature references at the end of this paper.

2 This name is recommended by the Committee on Carbohydrate Nomenclature appointed by the Divisions of Biological Chemistry, Chemical Education, and Sugar Chemistry and Technology of the American Chemical Society.
} 


\section{Journal of Research of the National Bureau of Standards}

from $D$-gulose in structure and configuration merely in that it contains the group $\mathrm{HCOH}$, having the D-glycero configuration, in the chain attached to the pyranose ring. Furthermore, we have found that the methyl D-glycero-D-gulo-aldoheptosides, like the configurationally related methyl $D$-gulosides form crystalline compounds with calcium chloride [2]. It therefore seemed of interest to determine whether the effect of calcium chloride on D-glycero-D-gulo-aldoheptose was similar to its effect on the configurationally related $D$-gulose, and to attempt the preparation of a crystalline calcium chloride compound of the unknown $\alpha$-D-glycero- $D$-gulo-aldoheptose, a substance of interest for the correlation of optical rotation and structure in the sugar group.

\section{EFFECT OF CALCIUM CHLORIDE ON THE OPTICAL ROTATION OF D-GLYCERO-D-GULO-ALDOHEPTOSE}

Measurements of the equilibrium optical rotation of $D$-glycero- $D$ gulo-aldoheptose in the presence of various quantities of calcium chloride gave the results reported in table 1 , from which it may be observed that the equilibrium rotation depends primarily on the concentration of calcium chloride. Solutions containing no calcium chloride have a specific rotation of about -20 , those containing about $6.5 \mathrm{~g}$ of calcium chloride per $100 \mathrm{ml}$ are optically inactive, and those containing more calcium chloride are dextrorotatory. The variation in the equilibrium rotation of $D$-glycero-D-gulo-aldoheptose in the presence of calcium chloride may be expressed approximately by the empirical equation

$$
[\alpha]_{D}^{20}=-20.2+3.54 m-0.067 m^{2},
$$

where $[\alpha]_{D}^{20}$ is the equilibrium rotation of the sugar, and $m$ is the number of grams of anhydrous calcium chloride per $100 \mathrm{ml}$ of solution. One of us has found the specific rotation of $D$-gulose in the presence of calcium chloride to be $[\alpha]_{D}^{20}=-26.4+3.73 \mathrm{~m}$. A comparison of the two equations reveals that calcium chloride alters the rotations of $D$-glycero-D-gulo-aldoheptose and $D$-gulose to about the same degree and in the same direction.

TABLE 1.-Effect of calcium chloride upon the equilibrium rotation of D-glyceroD-gulo-aldoheptose ${ }^{\mathrm{a}}$

$$
[a]_{D}^{20}=-20.2+3.54 m^{b}-0.067 m^{2} \text {. }
$$

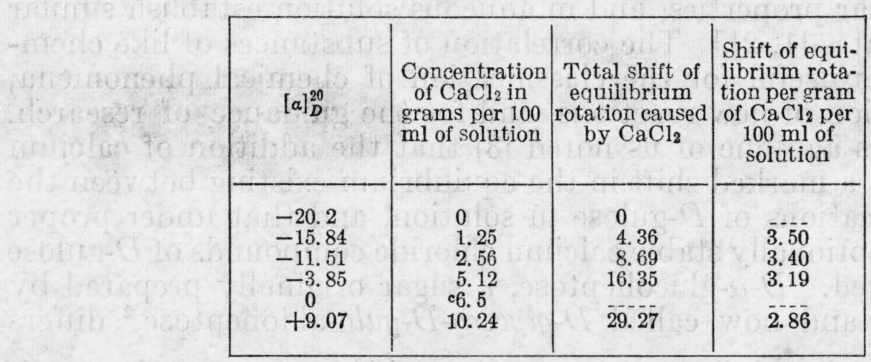

a Four $\mathrm{g}$ of sugar dissolved in $100 \mathrm{ml}$ of solution containing the amount of $\mathrm{CaCl}_{2}$ given. b $m$ is the concentration of $\mathrm{CaCl}_{2}$ in grams per $100 \mathrm{ml}$ of solution.

- Value calculated from above equation. 
The effect of calcium chloride on the optical rotations of these sugars is much greater than the effect on the optical rotations of most sugars. For instance, Murschhauser [5] found the equilibrium specific rotation of $D$-glucose to be +52.8 in water and +56.0 in $2 \mathrm{~N}$ calcium chloride, a change of only $0.29^{\circ}$ per gram of calcium chloride per $100 \mathrm{ml}$ of solution.

If calcium chloride alters the optical rotation by shifting the equilibrium between the different forms of the sugar in solution, the change in optical rotation caused by a change in the concentration of calcium chloride should take place at the same rate as the mutarotation of the sugar. Measurements of the mutarotation of D-glycero-D-guloaldoheptose, after dilution of a solution containing $8 \mathrm{~g}$ of the sugar and $10 \mathrm{~g}$ of calcium chloride per $100 \mathrm{ml}$, are reported in table 2 . It will be noted that the mutarotation follows the course of a first-order reaction. A similar change, but in the reverse direction, takes place when calcium chloride is added to an equilibrium solution of $D$ glycero-D-gulo-aldoheptose. In either case, the mutarotation coefficient is in accord with that for the mutarotation of freshly dissolved crystalline $\beta$-D-glycero-D-gulo-aldoheptose. The similarity of the $D$-gulose and $D$-glycero-D-gulo-aldoheptose is illustrated further by the curves in figures 1 and 2 , which show the mutarotations of the two sugars and the changes in optical rotation that take place when the equilibrium solutions of the sugars, containing calcium chloride, are diluted with either water or ethyl alcohol. In both cases upon dilution with water the optical rotation shifts toward the left, whereas upon dilution with alcohol it shifts toward the right.

TABLE 2.-Mutarotation of D-glycero-D-gulo-aldoheptose, in solution with calcium chloride, after dilution with water

[A solution containing $8 \mathrm{~g}$ of the sugar and $10 \mathrm{~g}$ of $\mathrm{CaCl}_{2}$ in $100 \mathrm{ml}$ in equilibrium at $20^{\circ} \mathrm{C}$ was diluted with water to 5 volumes, and the changes in optical rotation were measured, using a 4-dm tube.]

${ }^{\circ} S=+3.89 \times 10^{-.0079 t}-2.40$.

$[a]_{D}^{80}={ }^{\circ} S \times 5.426$.

\begin{tabular}{|c|c|c|}
\hline Time & $\begin{array}{l}\text { Observed } \\
\text { reading }\end{array}$ & $m_{1} \mathrm{a} \times 10^{3}$ \\
\hline $\begin{array}{l}\quad \text { Minutes } \\
3.6 \\
11.8 \\
21.0 \\
46.2 \\
62.9 \\
91.8 \\
123 \\
\infty\end{array}$ & $\begin{array}{l}{ }^{\circ} \mathrm{S} \\
+1.24 \\
+1.04 \\
+0.72 \\
+.25 \\
-.18 \\
-.74 \\
-1.16 \\
-1.69 \\
-1.99 \\
-2.40\end{array}$ & $\begin{array}{r}7.9 \\
8.2 \\
7.9 \\
7.8 \\
7.9 \\
7.9 \\
8.0 \\
7.9 \\
\end{array}$ \\
\hline A verage......... & .... & 7.9 \\
\hline
\end{tabular}

In a control experiment, a solution containing $8 \mathrm{~g}$ of $D$-glycero- $D$ gulo-aldoheptose in $100 \mathrm{ml}$ of water, in the absence of calcium chloride, was diluted to 5 volumes with water. The specific rotation changed in the course of several hours from -19.5 to -21.0 . This change is far less than that observed in the presence of calcium chloride. 


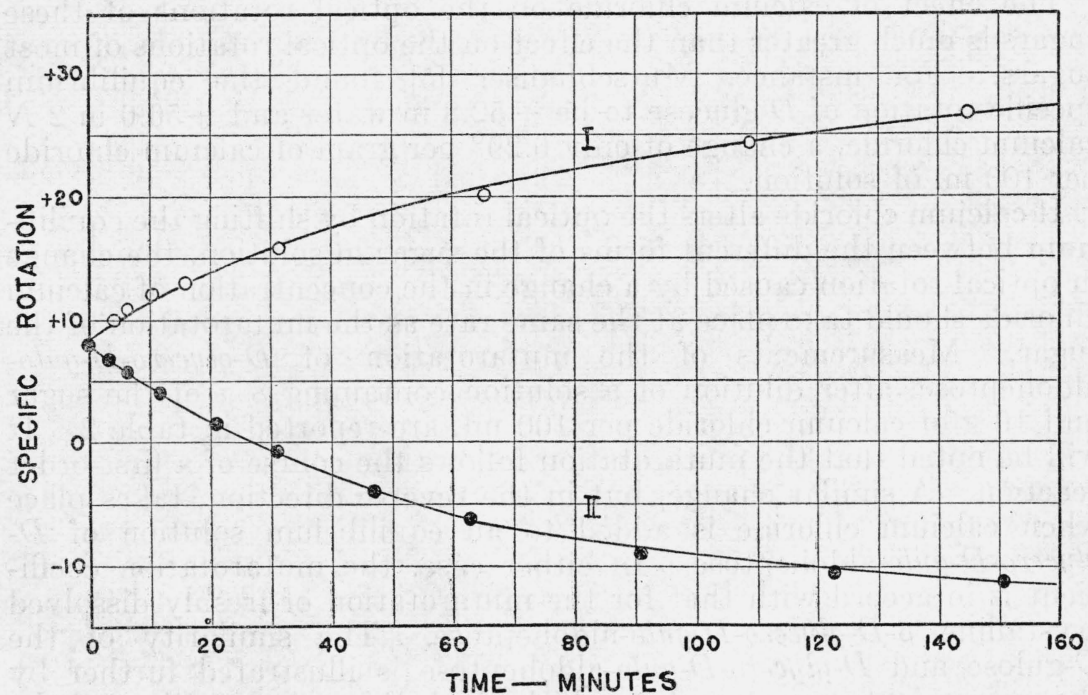

FIGURE 1.-Effect of dilution upon a calcium chloride-containing equilibrium solution of D-glycero-D-gulo-aldoheptose.

An equilibrium solution containing $8 \mathrm{~g}$ of the sugar and $10 \mathrm{~g}$ of $\mathrm{CaCl}_{2}$ per $100 \mathrm{ml}$ of solution was treated as follows: I. Diluted to 10 volumes with absolute alcohol. II. Diluted to 10 volumes with water.

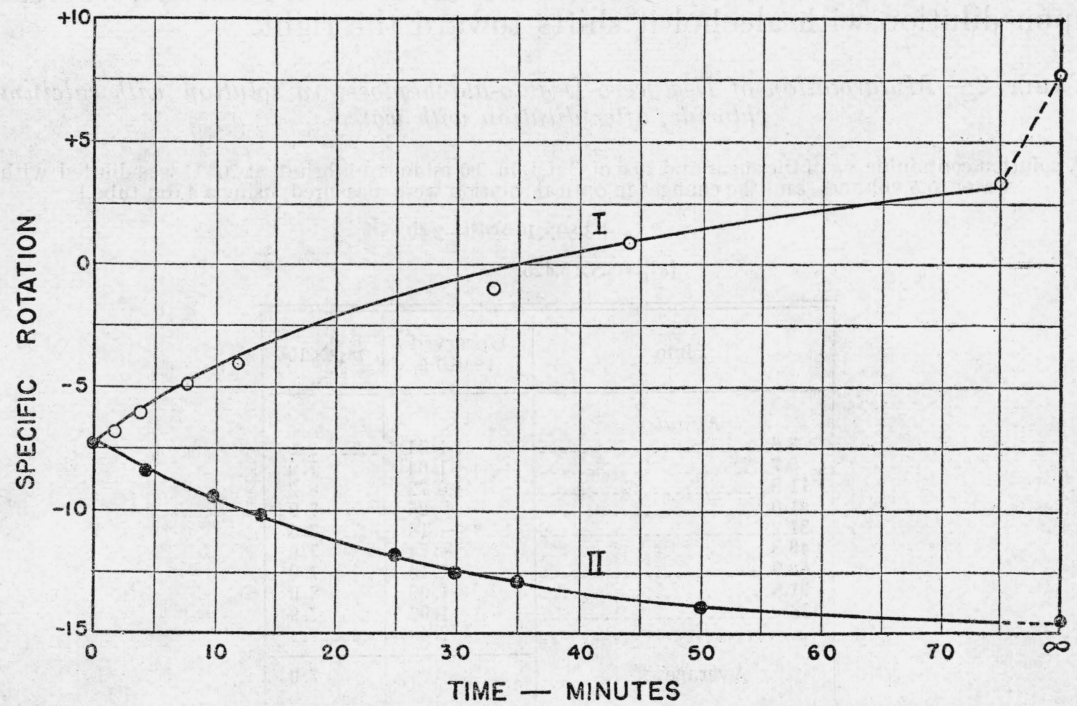

Figure 2.-Effect of dilution upon an equilibrium solution of D-gulose. $\mathrm{CaCl}_{2} \cdot \mathrm{H}_{2} \mathrm{O}$.

An equilibrium solution containing $10.64 \mathrm{~g}$ of $\alpha$ - $D$ - gulose. $\mathrm{CaCl}_{2} \cdot \mathrm{H}_{2} \mathrm{O}$ per $100 \mathrm{ml}$ of solution was treated as follows: I. Diluted to 5 volumes with absolute ethyl alcohol. II. Diluted to 10 volumes with water.

Attempts to ascertain the effect of alcohol on the equilibrium state of the free sugar were unsuccessful because crystallization of the sugar occurred before optical-rotation measurements could be made.

It is evident that aqueous solutions containing high concentrations of calcium chloride have a larger proportion of the alpha modification 
of the sugar than solutions containing less calcium chloride. The conclusion may be drawn that calcium chloride causes a disturbance in the equilibrium state between the two modifications, possibly because of greater affinity for the alpha isomer than for the beta. Dilution with water decreases the concentration of calcium chloride and shifts the equilibrium toward the beta isomer. The change in optical rotation that occurs on dilution with alcohol may arise from a smaller degree of dissociation of the calcium chloride compound of the alpha modification in alcohol than in water, or the change may be explained by the assumption that combination of the alcohol with the water increases the effective concentration of the calcium chloride. However, the situation is complex, and any interpretation of the effect of dilution without additional experimental evidence is purely hypothetical.

\section{CRYSTALLINE CALCIUM CHLORIDE COMPOUNDS OF D-GLYCERO-D-GULO-ALDOHEPTOSE}

$D$-gulose readily forms two crystalline calcium chloride compounds, $\alpha$ - $D$-gulose $\cdot \mathrm{CaCl}_{2} \cdot \mathrm{H}_{2} \mathrm{O}$ and ( $D$-gulose $)_{2} \mathrm{CaCl}_{2}$. The first of these compounds contains the alpha-pyranose modification, and the second seems to contain both the alpha-pyranose and the unknown betapyranose modification. When attempts were made to prepare similar compounds of $D$-glycero-D-gulo-aldoheptose, two crystalline calcium chloride compounds were obtained, but they do not appear to be strictly analogous to those of $D$-gulose. One of the compounds, $\beta-D$ glycero-D-gulo-aldoheptose. $\mathrm{CaCl}_{2} .2 \mathrm{H}_{2} \mathrm{O}$, was obtained in the pure state; the other was obtained only in a crystalline mixture, the optical rotation of which changed with time and in a direction opposite to that of mutarotation of the beta isomer. Optical-rotation measurements of the first compound, $\beta-D$-glycero-D-gulo-aldoheptose. $\mathrm{CaCl}_{2}$. $2 \mathrm{H}_{2} \mathrm{O}$, are given in table 3. The initial rotation, -15.8 , corresponds to a specific rotation of -26.9 for the heptose component. This is only slightly less than that of the pure beta-pyranose modification $(-28.7)$. Furthermore, the mutarotation which follows dissolution of the calcium chloride compound is like that of $\beta$-D-glycero-D-guloaldoheptopyranose in that it follows the course of a first-order reaction, and the mutarotation coefficient in water saturated with carbon dioxide, $m_{1}=0.0072$, is in accord with that of the free sugar. Hence it may be concluded that the new calcium chloride compound has the beta-pyranose structure.

Since the measurements of optical rotation described above show that the equilibrium state of solutions of $D$-glycero- $D$-gulo-aldoheptose is shifted by calcium chloride in the direction of the alpha isomer, it was to be expected, as in the case of $D$-gulose, that a calcium chloride compound crystallizing from solution would contain the alpha modification. The fact that a calcium chloride compound of the beta modification separates readily shows that both modifications of the sugar combine with calcium chloride and that the compound actually obtained depends on the conditions and the presence of seed crystals. 
TABLE 3.-Mutarotation of $\beta$-D-glycero-D-gulo-aldoheptose. $\mathrm{CaCl}_{2} .2 \mathrm{H}_{2} \mathrm{O}$ $4 \mathrm{~g}$ per $100 \mathrm{ml}$ at $20^{\circ} \mathrm{C}$, read in a 4 -dm tube.

$$
\begin{aligned}
{ }^{\circ} S & =-3.0 \times 10^{-.0072 t}-4.3 . \\
{[\alpha]_{D}^{20} } & =-6.5 \times 10^{-.0072 t}-9.3 .
\end{aligned}
$$

\begin{tabular}{|c|c|c|}
\hline Time & $\begin{array}{l}\text { Observed } \\
\text { reading }\end{array}$ & $m_{1} \times 10^{3}$ \\
\hline $\begin{array}{l}\text { Minutes } \\
\text { 4. } 4 \text {. } \\
13.9 \\
30.8 \\
44.5 \\
60.7 \\
75.2 \\
92.0\end{array}$ & $\begin{aligned} & \circ S \\
&--7.10 \\
&-6.69 \\
&-6.54 \\
&-6.14 \\
&-5.75 \\
&-5.46 \\
&-5.17 \\
&-4.99 \\
&-4.31\end{aligned}$ & $\begin{array}{r} \\
7.8 \\
7.2 \\
6.9 \\
7.2 \\
6.8 \\
7.2 \\
7.0 \\
\end{array}$ \\
\hline Average & & 7.2 \\
\hline
\end{tabular}

\section{PREPARATION OF $\beta$-D-GLYCERO-D-GULO-ALDOHEP- TOSE. $\mathrm{CaCl}_{2} \cdot 2 \mathrm{H}_{2} \mathrm{O}$}

An aqueous solution of $21 \mathrm{~g}$ of $D$-glycero- $D$-gulo-aldoheptose and $14.7 \mathrm{~g}$ of $\mathrm{CaCl}_{2} .2 \mathrm{H}_{2} \mathrm{O}$ was concentrated in vacuum to a thick sirup. ${ }^{3}$ Two volumes of ethyl alcohol was added, and the material allowed to stand in a desiccator until crystallization took place, after which the crystals were separated on a filter and washed with ethyl alcohol. The yield was $25.5 \mathrm{~g}$.

The $\beta$-D-glycero-D-gulo-aldoheptose calcium chloride compound was recrystallized by concentrating an aqueous solution in vacuum to a thick sirup, adding 2 volumes of ethyl alcohol, and allowing the sirup to crystallize in motion over the course of several days. The compound crystallizes in elongated rectangular plates that are very soluble in water and less so in ethyl alcohol. When the crystalline compound was dissolved in a few drops of water on a microscope slide, and the water allowed to evaporate, it was noted that the crystals which separated had the appearance of those of $\beta$-D-glycero-D-guloaldoheptose. Subsequent work showed that free $\beta$-D-glycero- $D$-guloaldoheptose crystallizes from dilute aqueous solutions of the calcium chloride compound.

Analysis: Calculated for $\mathrm{C}_{7} \mathrm{H}_{14} \mathrm{O}_{7} . \mathrm{CaCl}_{2} .2 \mathrm{H}_{2} \mathrm{O}: \mathrm{C}, 23.54 ; \mathrm{H}, 5.08$; $\mathrm{Ca}, 11.22 ; \mathrm{Cl}, 19.85$. Found: C, 23.56; H, 4.97; Ca, 11.18; Cl, 19.83 .

\section{REFERENCES}

[1] H. S. Isbell, J. Research NBS 18, 505 (1937) RP990.

[2] H. S. Isbell and H. L. Frush, J. Research NBS 24, 125 (1940) RP1274.

[3] H. S. Isbell, BS J. Research 5, 741 (1930) RP226.

[4] E. Fischer, Liebigs Ann. Chem. 270, 64 (1892).

[5] H. Murschhauser, Biochem. Z. 136, 66 (1923).

Washington, July 5, 1943.

\footnotetext{
${ }^{3}$ The first crystals of this compound were obtained from solutions containing a larger proportion of calcium chloride. In subsequent preparations, however, the sugar and calcium chloride were added in the molecular proportion found in the compound.
} 